\title{
Prevalence of parafunctional habits and temporomandibular dysfunction symptoms in patients attending a tertiary headache clinic
}

\author{
Yára Dadalti Fragoso', Heloísa Helena Carvalho Alves², \\ Sidney Oliveira Garcia², Alessandro Finkelsztejn ${ }^{3}$
}

\begin{abstract}
Objetive: To investigate the most prevalent forms of headache in a tertiary outpatient service, and to assess the frequency of associated parafunctional habits and temporomandibular dysfunction symptoms (TMD). Method: All new patients referred to the Headache Outpatient Service in UNIMES during 2008 were prospectively assessed by the neurologist and the dental surgeon. Results: Eighty new patients were assessed; chronic migraine and episodic migraine without aura were the most prevalent conditions, accounting for $66.3 \%$ of all cases. There was significantly higher use of analgesics/days for the chronic migraine patients. The prevalence of parafunctional habits was $47.5 \%$ and the prevalence of TMD symptoms was $35 \%$. Conclusion: The high prevalence of primary headaches, parafunctional habits and TMD symptoms and the inadequate use of analgesic drugs suggest that primary healthcare units need further training in the field of headache and orofacial pain.
\end{abstract}

Key words: headache, migraine, temporomandibular dysfunction.

Prevalência de hábitos parafuncionais e de sintomas de disfunção temporomandibular em pacientes atendidos em um ambulatório terciário de cefaléias

\section{RESUMO}

Objetivo: Investigar as formas prevalentes de cefaléia em um ambulatório terciário e analisar a frequência de hábitos parafuncionais e de sintomas de disfunção temporomandibular (DTM) associados. Método: Todos os pacientes novos encaminhados ao Serviço de Cefaléias da UNIMES durante 2008 foram avaliados de forma prospectiva pelo neurologista e pelo cirurgião dentista. Resultados: Oitenta pacientes novos foram avaliados; enxaqueca crônica e enxaqueca episódica sem aura foram as condições mais prevalentes, perfazendo $66,3 \%$ de todos os casos. Houve uso significativamente alto de analgésicos/dias pelos pacientes com enxaqueca crônica. A prevalência de hábitos parafuncionais foi 47,5\% e a prevalência de sintomas de DTM foi 35\%. Conclusão: A alta prevalência de cefaléias primárias, hábitos parafuncionais, sintomas de DTM e o uso inadequado de drogas analgésicas sugerem que as unidades básicas de saúde necessitam maior treinamento no campo da cefaléia e da dor orofacial.

Palavras-chave: cefaléia, enxaqueca, disfunção temporomandibular.

Correspondence

Yara Dadalti Fragoso

Rua da Constituição 374

11015-470 Santos SP - Brasil

E-mail: yara@bsnet.com.br

Received 4 July 2009

Received in final form 14 October 2009

Accepted 26 November 2009
Patients presenting more than one type of headache and/or orofacial pain are likely to remain without proper diagnosis and treatment in non-specialized healthcare units. The additional conditions of de- pression, anxiety, sleep disturbances, fatigue, etc (typical of long-lasting chronic pain syndromes), make it even more difficult for general practitioners to efficiently approach and manage such cases ${ }^{1}$.

${ }^{1}$ Neurology, Universidade Metropolitana de Santos, Santos SP, Brazil; ${ }^{2}$ Dentistry School, Universidade Santa Cecília de Santos, Santos SP, Brazil; ${ }^{3}$ Hospital de Clínicas de Porto Alegre, Porto Alegre RS, Brazil. 
Among the most frequent associations of cephalic pain $^{2}$, it is important to cite migraine and tension type headache $(\mathrm{TTH})^{3}$, migraine and temporomandibular dysfunction (TMD) $)^{4}$, and TTH and TMD ${ }^{5}$. The most recent studies in the literature emphasize the importance of a multidisciplinary approach towards head and neck pain, including a neurologist and a dental surgeon, both with special skills in assessing these patients ${ }^{6-8}$. These recent efforts are generating many new questions regarding classification ${ }^{9}$ and treatment ${ }^{10}$ of these frequently combined conditions.

The present study had the aim of adding to the discussion, through presenting the results from dental evaluations on a relatively large number of patients attending a tertiary headache clinic at a university.

\section{METHOD}

This study was approved by the Ethics Committee of Universidade Metropolitana de Santos and Universidade Santa Cecilia, and was registered in a national research database (CNPq). Written consent was obtained from all participants.

Every new patient, aged 18 or over, who was referred to the Headache Outpatient Service in UNIMES during the year 2008, was offered an evaluation by the dental surgeon from UniSanta on the same day, at the same place. The evaluation consisted of anamnesis, application of a specific questionnaire and clinical assessment to identify parafunctional habits and TMD symptoms. All of these patients are undergoing treatment for their headaches, and those who presented dental disorders and/or TMD symptoms were referred for specialized evaluation and treatment.

Headache classification was performed in accordance with the International Classification of Headache Disorders, $2^{\text {nd }}$ edition (ICHD-II) ${ }^{11}$.

TMD symptoms and parafunctional habits were assessed using a short version of the Research Diagnostic Criteria for Temporomandibular Disorders (RDC/ TMD) $)^{12}$, adapted and validated for use in Portuguese ${ }^{13}$.

There is no consensus on the definition of the exact quantities of each drug that are required to qualify as "excessive use of medication"14. However, for the purpose of the present study, this was considered to be more than ten doses/days per month of any drug that had been used to relieve the cephalic pain over the preceding three months.

All data were sent to an independent neurologist who analyzed the statistical significance of the findings. The ttest was used to calculate continuous data and the chisquare test, for categorical data. Correlations were assessed using the Pearson and Spearman tests. Results were considered significant when $\mathrm{p}<0.05$.

All evaluations were blind to the other examiners, i.e. the neurologist evaluating the headache, the dental surgeon and the neurologist analyzing all the data were not aware of each other's data or results.

\section{RESULTS}

Eighty patients were assessed by both the neurologist and the dental surgeon. The group consisted of 70 females and 10 males, with an average age of 47 years $( \pm 16.2)$. All the patients had had over one year of headaches, with at least one attack every ten days at the time of our consultation, thus characterizing all cases as chronic or frequently recurring headaches.

A summary of the neurological diagnoses for these headaches is presented in Table. Briefly, migraine was the most prevalent type of headache. Although chronic migraine was the most frequent condition (40\% of all patients), episodic migraine with aura (1.3\%) and episodic migraine without aura (26.3\%) were also present, therefore making "migraine" the diagnosis of over three quarters of our cases. Patients with episodic migraine with or without aura presented very frequent attacks but did not fulfill the criteria for chronic migraine. None of the migraine patients knew how to make proper use of abortive medication, and unsuccessfully used high doses at the time when the pain was at its most intense.

TTH was present in $16.3 \%$ of all headache cases, and only the chronic presentation of TTH was seen in these patients. Tenderness in the pericranial muscles was observed in all of these chronic TTH patients.

Excessive use of medications (mainly simple analgesics) was observed in $43.8 \%$ of all patients, with doses ranging from 15 to over 75 tablets per month. This finding was significantly higher for women than for men $(p<0.001)$. Although the HIS classification ${ }^{11}$ considers chronic migraine to be exclusive of patients who do not make excessive use of pain killers, the present study took

Table. Headache diagnoses according to the ICHD-II, 2004, among 80 patients at the UNIMES Headache Outpatient Service.

\begin{tabular}{lcc}
\hline Diagnosis & $\begin{array}{c}\text { Number of } \\
\text { patients }\end{array}$ & Percentage \\
\hline Chronic migraine & 32 & 40 \\
Episodic migraine without aura & 21 & 26.3 \\
Chronic tension type headache & 13 & 16.3 \\
(with pericranial muscle tenderness) & & \\
Cervicogenic headache & 2 & 2.5 \\
Hemicrania continua & 2 & 2.5 \\
Trigeminal neuralgia (primary) & 2 & 2.5 \\
Cluster headache & 1 & 1.3 \\
Episodic migraine with aura & 1 & 1.3 \\
Primary stabbing headache & 1 & 1.3 \\
\hline
\end{tabular}


into consideration the revised and broader criteria proposed in $2006{ }^{15}$. Chronic migraine patients (according to the abovementioned revised criteria) consumed significantly more analgesics/days than did the patients with episodic migraine $(\mathrm{p}<0.001)$ and patients with chronic TTH $(\mathrm{p}<0.001)$.

The odontological assessment of these patients identified many cases in need of proper dental care, which was expected in this university outpatient service that attends mainly the lower socioeconomic classes. The prevalence of TMD symptoms among these patients was $35 \%$, and parafunctional habits (nail biting, teeth grinding etc) were present in $47.5 \%$. These conditions were more frequent among women $(\mathrm{p}<0.001$, both for TMD symptoms and for parafunctional habits). Smoking was less frequent among women than among men $(\mathrm{p}<0.001)$.

There was no clear association between excessive use of analgesics/days for patients with concomitant headache and TMD symptoms $(\mathrm{p}=0.19)$.

\section{DISCUSSION}

The prevalence of headaches in our tertiary headache outpatient service was similar to that described in another Brazilian study ${ }^{16}$. The significantly higher frequency of medication overuse among chronic migraine patients reflects a worldwide observation ${ }^{17,18}$.

The association between primary headaches (in particular $\mathrm{TTH}^{5}$ ) and TMD has been the subject of study for many researchers, as reviewed recently by Mongini ${ }^{19}$. Although the lines of study may differ, there seems to be agreement that these conditions overlap with anxiety, depression, maladaptive coping, inability to communicate with others and deal with life events, and common pathophysiological origins ${ }^{7,19-25}$. The results from the present study further add to the discussion on the very high prevalence of signs and symptoms of TMD among primary headache patients. In relation to the findings cited earlier in this paper, regarding the association between primary headaches and TMD symptoms, our results do not show such a high association (it was around $50 \%$ in many of the other authors' series). However, we consider that our results show a relatively high association between these conditions, since over a third of our primary headache patients presented TMD symptoms and nearly half of all of these patients presented parafunctional habits. However, it must be considered that the degree of association of TTH/TMD observed in the population studied here does not reflect the degree of the association TTH/ TMD in the general population. However, the population study recently carried out by Queiroz et al. ${ }^{26}$ shows a similar prevalence of TTh in Brazil. Our patients were all cases of chronic TTH, with many years of headache history. The simpler cases of TTH do not usually come to tertia- ry headache clinics and their prevalence of TMD/TTH is, as yet, still a matter under investigation.

Although no controlled trial has been performed ${ }^{27}$, parafunctional habits seem to be a high risk factor for $\mathrm{TMD}^{28}$. At least among adolescents, TMD and parafunctional habits were found to be significantly more prevalent in females ${ }^{29}$. The present study showed the same gender-related findings for adults with primary headaches.

It is of crucial importance to have evaluations both from the neurologist and from the dental surgeon when attending headache patients. The most successful treatment in cases of two or more forms of associated headache in one given patient will obviously be provided by all specialists working together. In fact, a multidisciplinary approach towards headache patients is likely to provide the best results whenever a headache patient requires specialized healthcare management.

Our previous study, with a much smaller number of patients, suggested that there could be an association between excessive use of analgesics among patients presenting both primary headache and TMD symptoms ${ }^{30}$. This finding could not be confirmed in the present series of patients, and it should be the subject of future, larger studies. We intend to increase the number of males in our group of patients, since the female-to-male ratio in this study was 7:1, thus allowing a much better assessment of all the parameters among women.

Finally, it is very important to highlight the inappropriateness of using a tertiary headache clinic for patients such as those seen in our service in 2008. The vast majority of these patients presented primary headaches that had not received adequate treatment and therefore could not be considered to be refractory headache patients. There were many cases of medication overuse, and none of them had been managed adequately prior to referral. The oral condition of these patients should have been enough for the referring general practitioners to consider sending the patients for evaluations by dental surgeons. No cases of headaches possibly relating to increased intracranial pressure were referred. In fact, if any such patients had been referred, they might have been unable to book a consultation because of the high number of cases that should not have been sent to the tertiary center without any attempt at treatment. This inappropriate use of specialized headache units reflects inadequacy within basic medical and odontological education ${ }^{31,32}$, which is made worse by pressure from patients for consultations with specialists $^{32}$.

\section{REFERENCES}

1. Broggi G. Pain and psycho-affective disorders. Neurosurgery $2008 ; 62$ (Suppl 3): S901-S919.

2. Kang JK, Ryu JW, Choi JH, Merrill RL, Kim ST. Application of ICHD-II criteria for headaches in a TMJ and orofacial pain clinic. Cephalalgia 2009:29:550-555. 
3. Larner AJ. Concurrence of primary headaches: Lane and Davies (2006) revisited. J Headache Pain 2009;10:133.

4. Weinberg MA, Gopinathan G. Recognition and treatment of migraine patient in dental practice. N Y State Dental J 2009;75:28-33.

5. Cooper BC, Kleinerg I. Relationship of temporomandibular disorders to muscle tension-type headaches and a neuromuscular orthosis approach to treatment. Cranio 2009;27:101-108.

6. Di Paolo C, Di Nunno A, Vanacori N, Brutti G. ID migraine questionnaire in temporomandibular disorders with craniofacial pain: a study by using a multidisciplinary approach. Neurol Sci 2009 [e-pub ahead of printing].

7. Graff-Radford SB. Temporomandibular disorders and other causes of facial pain. Curr Pain Headache Rep 2007;11:75-81.

8. Ballegaard V, Thede-Schmidt-Hansen P, Svensson P, Jensen R. Are headache and temporomandibular disorders related? A blinded study. Cephalalgia 2008;28:832-841.

9. Benoliel R, Birman N, Eliav E, Sharav Y. The International Classification of Headache Disorders: accurate diagnosis of orofacial pain? Cephalalgia 2008;28:752-762.

10. Klasser GD, Greene CS. Oral appliances in the management of temporomandibular disorders. Oral Surg Oral Med Oral Pathol Oral Radiol Endod 2009;107:212-223.

11. Headache Classification Committee. The international classification of headache disorders, cranial neuralgia and facial pain. Cephalalgia 2004;2(Suppl 1):S1-S160.

12. Dworkin SF, Le Resche L. Research diagnostic criteria for temporomandibular disorders: review, criteria, examinations and specifications, critique. J Craniomandib Disord 1992;6:301-355

13. Lucena LBS, Kosminsky M, Costa LJ, Goes PSA. Validation of the Portuguese version of the RDC/TMD Axis II questionnaire. Braz Oral Res 2006;20: 312-317.

14. Bigal ME, Rappaport AM, Sheftel FD, Tepper SJ, Lipton RB. Transformed migraine and medication overuse in a tertiary headache centre: clinical characteristics and treatment outcomes. Cephalalgia 2004;24:483-490.

15. Olesen J, Bousser M-G, Diener H-C et al. New appendix criteria for a broader concept of chronic migraine. Cephalalgia 2006;6:742-746.

16. Felício AC, Bichuetti DB, Santos WA, Godeiro Junior CO, Marin LF, Carvalho DS. Epidemiology of primary and secondary headaches in a Brazilian tertiary-care Center. Arq Neuropsiquiatr 2006;64:41-44.

17. Allena M, Katsarava Z, Nappi G; COMOESTAS Consortium. From drug-induced headache to medication overuse headache. A short epidemiological review, with a focus on Latin American countries. J Headache Pain 2009:10:71-76.
18. Katsarava Z, Holle D, Diener HC. Medication overuse headache. Curr Neurol Neurosci Rep 2009;9:115-119.

19. Mongini F. Temporomandibular disorders and tension-type headache. Curr Pain Headache Rep 2007;11:465-470.

20. Torelli P, Abrignani G, Castellini P, Lambru G, Manzoni GC. Human psyche and headache: tension-type headache. Neurol Sci 2008;29(Suppl 1):S93-S95.

21. Heckman BD, Holroyd KA. Tension-type headache and psychiatric comorbidity. Curr Pain Headache Rep 2008;29(Suppl 1):S93-S95.

22. Jerjes W, Madland G, Feinmann C, Hopper C, Kumar M, Upile T, Kudari M, Newman S. A psychological comparison of temporomandibular disorder and chronic daily headache: are there targets for therapeutic interventions? Oral Surg Oral Med Oral Pathol Oral Radiol Endod 2007;103:367-373.

23. Kanehira $\mathrm{H}$, Agariguchi $\mathrm{A}$, Kato $\mathrm{H}$, Yoshimine $\mathrm{S}$, Inoue $\mathrm{H}$. Association between stress and temporomandibular disorder. Nihon Hotetsu Shika Gakkai Zasshi 2008;52:375-380.

24. Carlson CR. Psychological considerations for chronic orofacial pain. Oral Max illofac Surg Clin North Am 2008;20:185-195.

25. Glaros AG, Urban D, Locke J. Headache and temporomandibular disorders: evidence for diagnostic and behavioural overlap. Cephalalgia 2007;27:542-549.

26. Queiroz LP, Peres MFP, Piovesan EJ, et al. A nationwide population-based study of tension type headache in Brazil. Headache 2009;49:71-78.

27. Manfredini D, Landi N, Romagnoli M, Cantini E, Bosco M. Etiopathogenesis of parafunctional habits of the stomatognathic system. Minerva Stomatol 2003; 52:339-345.

28. Poveda Roda R, Bagan JV, Díaz Fernández JM, Hernández Bazán S, Jiménez Soriano Y. Review of temporomandibular joint pathology. Part l: classification, epidemiology and risk factors. Med Oral Patol Oral Cir Bucal 2007;12:292-298.

29. Winocur E, Littner D, Adams I, Gavish A. Oral habits and their association with signs and symptoms of temporomandibular disorders in adolescents: a gender comparison. Oral Surg Oral Med Oral Pathol Oral Radiol Endod 2006; 102:482-487.

30. Alves HHC, Zanata EC, Garcia SO, Homem K, Fragoso YD. Prevalence of temporomandibular disorders symptoms in primary headache patients attended in a public tertiary care outpatient clinic. Migr \& Cefaleias 2008;11:18-21.

31. De Klippel N, Jansen JP, Carlos JS. Survey to evaluate diagnosis and management of headache in primary care: Headache Management Pattern programme. Curr Med Res Opin 2008;24:3413-3422.

32. Ridsdale L, Clark LV, Dowson AJ, et al. How do patients referred to neurologists for headache differ from those managed in primary care? Br J Gen Pract 2007:57:388-395. 